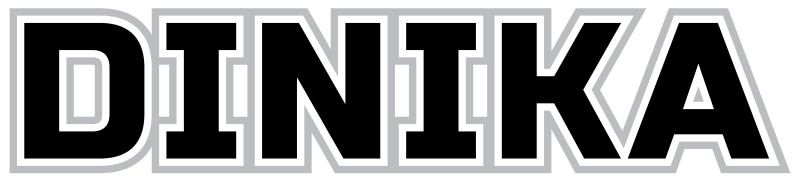

Academic Journal of Islamic Studies

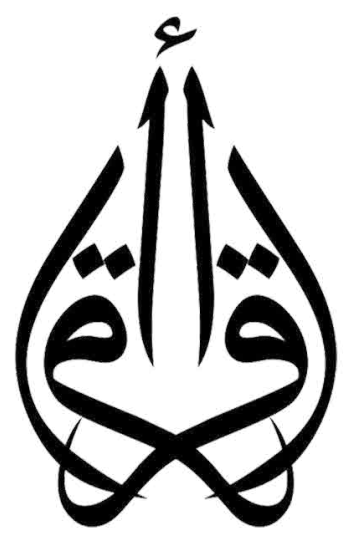


Volume 4, Number 3, September - December 2019 ISSN: 2503-42I 9 (p); 2503-4227 (e)

\section{DINIKA}

Academic Journal of Islamic Studies

\section{Table of Contents}

\section{Main Articles:}

Muslimab Beauty Veiling, Piety and Commodity in the New Indonesian

Public Sphere

Yuyun Sunesti

Competing Identity and Culture: The Formation of Forum Lingkar Pena and Komunitas Matapena in Indonesia

Nor Ismah

Ria Ricis and New Platform of Islamic Popular Culture

Wahyudi Akmaliah

\section{Articles:}

Perseteruan Memori Kolektif Kontestasi Islam dan Politik di

Tasikmalaya Pasca-Orde Baru

Amin Mudzakkir

Qital: Reinterpretasi Pendekatan Humanis

Ana Rahmawati, Azzah Nor Laila

The Characteristics of Philosophical Knowledge of The Qur'an and Prophetic Revelation According to Muni Laswad in His Book Islâm al-Falâsifa

Muhammad Makmun, Dessy Yanti Srie Budiningsih 


\title{
Perseteruan Memori Kolektif Kontestasi Islam dan Politik di Tasikmalaya Pasca-Orde Baru
}

\author{
Amin Mudzakkir \\ Pusat Penelitian Sumber Daya Regional (P2SDR) LIPI \\ email: amin004@lipi.go.id
}

\begin{abstract}
This paper aims to understand the post-New Order political Islam, by taking the case in Tasikmalaya from its historical and reactualization perspective. Maurice Halbwachs and Pierre Nora called the last thing as a memory, which is considered the antithesis of history. In practice, the boundary between history and memory is indeed blurred or obscured. For the analysis in this paper, these two things are positioned differently. The focus of the article is to understand the extent to which democracy works in local cultural values which may conflict with the views of liberal human rights. The case of Tasikmalaya is interesting to put in the context of "democratic communitarianism" and more broadly can be used to see tolerance in Indonesia through the lens of cooperation between universal human rights principles and religious interpretations that are grounded in communal experience.
\end{abstract}

Keywords: Tasikmalaya, political Islam, New Order, Collective Memory

\begin{abstract}
Abstrak
Tulisan ini bertujuan memahami Islam politik pasca-Orde Baru, dengan mengambil kasus di Tasikmalaya, dari perspektif sejarah dan reaktualisasinya. Maurice Halbwachs dan Pierre Nora menyebut hal terakhir itu sebagai memori, yang dianggap antitesis sejarah. Dalam praktiknya, batas antara sejarah dan memori memang kabur atau dikaburkan. Untuk analisis di tulisan ini, dua hal tersebut diposisikan berbeda. Fokus tulisan adalah memahami sejauh mana demokrasi bekerja dalam nilai-nilai kultural setempat yang mungkin bertentangan dengan pandangan HAM liberal. Kasus Tasikmalaya ini menarik untuk diletakkan dalam konteks "komunitarianisme demokratis" dan secara lebih luas dapat digunakan untuk melihat toleransi di Indonesia dengan kacamata kerjasama antara prinsip universal HAM dan interpretasi-interpretasi agama yang berpijak pada pengalaman komunal.
\end{abstract}

Kata kunci:Tasikmalaya, Islam politik, Orde Baru, Memori Kolektif 


\section{Pendahuluan}

Tulisan ini menyuguhkan suatu analisis yang melihat Islam politik di Tasikmalaya di era pasca-Orde Baru bukan hanya berdasarkan perspektif sejarah, tetapi, lebih penting dari itu, bagaimana sejarah kemudian direaktualisasi oleh para aktor kontemporer dalam aksi-aksi keagamaan dan politik mereka. Para penulis seperti Maurice Halbwachs (1992) danm Pierre Nora (1989: 7-24) menyebut hal terakhir itu sebagai memori, sesuatu yang justru sering berperan sebagai antitesis sejarah. Sementara sejarah lebih dipahami sebagai catatan tentang masa lalu yang diresmikan dan kemudian diterima secara publik, memori lahir dari subjektivitas personal. Dalam praktiknya, batas antara sejarah dan memori memang kabur, atau dikaburkan, meski untuk kepentingan analisis kita perlu melihatnya tetap sebagai dua hal yang berbeda.

Selain itu, tulisan ini juga melihat fenomena Islam politik tidak hanya dari sudut pandang hak asasi manusia (HAM) liberal. Lebih dari itu, tulisan ini berangkat dari keinginan untuk memahami sejauh mana demokrasi bisa bekerja dalam nilai-nilai kultural setempat yang dalam hal tertentu mungkin bertentangan dengan pandangan HAM liberal. Robert Hefner (2004) menyebut hal ini sebagai fenomena "komunitarianisme demokratis" yang menarik untuk dipertimbangkan dalam konteks negaranegara Muslim. Belakangan Jeremny Menchik (2006) juga menyarankan kita untuk melihat masalah toleransi di Indonesia tidak melulu dengan kacamata liberal, tetapi dengan lebih menekankan kemungkinan adanya kerjasama antara prinsip universal HAM dan interpretasi-interpretasi agama yang berpijak pada pengalaman komunal.

\section{Tasikmalaya Abad Ke-20}

Seperti kota-kota lain di Jawa, Sejak awal abad ke-20 Tasikmalaya telah berkembang sebagai kota kebangkitan ekonomi pribumi. Khususnya memasuki akhir dekade 1930-an, dibantu oleh adanya insentif yang diberikan oleh pemerintah kolonial, lahir para pengusaha yang bergerak 
terutama di bidang batik dan kerajinan tangan. Selain mendirikan koperasi, mereka pun berjejaring dengan sejawat mereka di kota-kota lainnya. Di antara koperasi yang terkemuka adalah koperasi Mitra Batik dan Mitra Payung. Koperasi yang disebut terakhir ini berkembang pesat pada tahun 1950-an, mendirikan pabrik yang menghasilkan sendiri kain mori, sebelum merosot di era Orde Baru dan akhirnya kolaps menjelang krisis moneter 1998 (Mudzakkir 2005).

Para pengusaha pribumi yang sedang bangkit tersebut mengartikulasikan pandangan politiknya melalui pergerakan-pergerakan kaum santri. Awalnya banyak dari mereka tergabung dalam Sarekat Islam (SI). Dalam peristiwa Cimareme, Garut, 1919 yang terkenal juga sebagai pemberontakan SI Afdelling B, beberapa haji terkemuka asal Tasikmalaya ikut terlibat. Diantaranya adalah Haji Ismail asal Manonjaya. Setelah SI meredup, mereka bergabung dengan organisasi-organisasi Islam modernis, seperti Muhammadiyah, Persatuan Islam (Persis), dan Persatuan Umat Islam (PUI), yang berdiri di kota itu pada tahun 1920-an. Nahdlatul Ulama (NU) muncul belakangan, yaitu awal 1930-an, namun bukan sebagai respons terhadap gerakan Islam modernis sebagaimana dilaporkan oleh Deliar Noer dalam konteks Indonesia secara umum (Noer 1996), melainkan sebagai kritik terhadap keberadaan Perkumpulan Guru Ngaji (PGN) yang sangat pro-pemerintah bentukan Bupati Tasikmalaya saat itu. Setelah kemerdekaan, Tasikmalaya adalah basis Masyumi. Pada Pemilu 1955 dan Pemilihan Daerah 1957, mereka memenangkan pemilihan, disusul NU, PNI, dan PKI. Para anggota organisasi Islam modernis umumnya menyalurkan aspirasi politiknya melalui partai ini. Sementara itu, pada saat yang sama, Tasikmalaya pada tahun 1950-an adalah wilayah yang tidak aman. Sejak Kartosuwiryo mendeklarasikan Darul Islam/ Tentara Islam Indonesia (DI/TII) pada 1949, dia menjadikan Tasikmalaya menjadi salah satu basisnya, terutama di daerah perdesaan/pegunungan. Sepanjang tahun 1950-an, terjadi sejumlah pertikaian bersenjata antara 
DI/TII dan anggota Tentara Nasional Indonesia (TNI). Awalnya banyak kalangan, termasuk tokoh agama, yang bergabung bersama Kartosuwiryo. Namun menjelang kekalahannya pada awal 1960-an, mereka menyerah. Salah satunya KH Maoshul Affandy, pendiri pesantren Miftahul Huda Manonjaya.

Pada masa Orde Baru, kekuatan-kekuatan ekonomi politik Islam dikendalikan secara ketat oleh pemerintah. Seperti juga di tempat lain, Golkar memenangkan pemilu secara berturut-turut, meski dalam Pemilu 1971 dan 1977 NU dan kemudian PPP masih cukup kuat. Namun terutama sejak para kyai NU beralih ke Golkar pada awal 1980-an, kemenangan partai penguasa tersebut tidak terbendung lagi. Dan seperti juga di tempat lain, pengaruh militer dalam perpolitikan Tasikmalaya selama Orde Baru sangat terasa. Pada periode itu hampir semua bupati berasal dari militer, biasanya bekas komandan kodim 0612 Tasikmalaya, atau didrop dari atas.

Selepas berakhirnya Orde Baru, berdasarkan UU No. 10 Tahun 2001, Kabupaten Tasikmalaya bersama dengan beberapa daerah lainnya "dimekarkan" sebagai bagian dari kebijakan otonomi daerah dan desentralisasi. Secara formal proses pemekaran berjalan relatif cepat karena telah ada Kota Administratif (Kotif) Tasikmalaya yang dibentuk berdasarkan PP. No. 22 Tahun 1976. Dengan demikian, Kota Tasikmalaya yang dibentuk pada 2001 adalah penerus Kotif Tasikmalaya yang telah ada sebelumnya, tetapi dengan tambahan wilayah. Sejak itu, secara administratif, terdapat Kabupaten Tasikmalaya dan Kota Tasikmalaya hingga sekarang.

\section{Kebangkitan Ulang Islam Politik}

Dari kilasan di atas, kita bisa melihat bahwa relasi Islam dan politik di Tasikmalaya telah mempunyai pijakan historis yang kuat. Namun di era Orde Baru, relasi tersebut agak terhenti, sebelum muncul kembali pada akhir tahun 1990-an seiring dengan menguatnya pengkonstruksian Tasikmalaya sebagai "kota santri”" (Hadad 1998). Pada tataran global, kita 
tahu bahwa sejak kolapsnya komunisme dan menguatnya globalisasi pada akhir abad ke-20, agama dan simbol-simbolnya mewarnai ruang publik, termasuk dalam politik. Jurgen Habermas, seorang filsuf Jerman terkemuka, menyebutnya sebagai kondisi-kondisi “post-sekuler" (Habermas 2008). Di Indonesia, kebangkitan Islam politik tersebut bahkan difasilitasi oleh negara, melahirkan kelompok-kelompok Muslim konservatif yang berwatak politis (Hefner 2001).

Di Tasikmalaya, kelompok-kelompok tersebut sebagai kelompok "ajengan bendo" karena pakaian khas yang dikenakannya. Mereka terdiri dari KH Asep Maoshul Affandy, KH Miftah Farid, KH Tb. Miftah Fauzi, KH Didi Abdul Madjid, KH Mahfud Sidik, KH Amang Baden, KH Jenjen, KH Abdul Jabbar, KH Azid Affandy. Mereka aktif berceramah dengan kritik sosial politik sebagai tema pokoknya. Mereka berbicara di hadapan publik mengenai kegagalan Orde Baru dan kemungkinan Islam sebagai solusi atas kegagalan itu. Namun mereka tidak lagi berbicara "negara Islam", melainkan "syariat Islam". Di tengah era kemerosotan rezim pada akhir 1990-an, mereka dengan cepat memperoleh pengaruh di tengah masyarakat setempat.

Peristiwa kerusuhan Tasikmalaya 1996 adalah momentum kebangkitan sentimen Islam politik tersebut. Peristiwa itu sendiri dipicu oleh hal sepele. Seorang santri yang merupakan anak polisi dihukum oleh guru ngajinya di Pesantren Riyadul Ulum Wadda'wah, Condong. Tidak terima atas perlakuan itu, si bapak yang polisi itu memanggil si guru ngaji anaknya di kantornya, Polres Tasikmalaya. Namun kabar yang beredar menyebutkan si bapak menyiksa si guru ngaji. Tidak menunggu lama setelah kabar beredar, ribuan orang terkumpul di kota, berdemonstrasi di depan kantor Polres. Namun tidak lama kemudian demonstrasi itu berubah menjadi aksi perusakan, tidak hanya terhadap kantor Polres, tetapi juga terhadap gereja-gereja dan toko-toko milik penduduk keturunan Tionghoa. Peristiwa ini sendiri bersamaan dengan serangkaian kerusuhan 
di Rengasdengklok, Situbondo, dan kota-kota lain pada masa akhir Orde Baru (Hadad 1998).

Dalam peristiwa kerusuhan tersebut, isu ketidakadilan ekonomi dimunculkan. Berhembus kesan bahwa para pengusaha keturunan Tionghoa telah mengambil alih posisi para pengusaha pribumi. Pengusaha keturunan Tionghoa seolah-olah dianakemaskan, sedangkan para pengusaha pribumi seakan-akan dianaktirikan. Kesan ini dikontraskan dengan narasi-narasi tentang kemajuan ekonomi para pengusaha pribumi di masa lalu. Dari sini sentimen rasisme dikembangkan, dicampur dengan sentimen agama yang kental.

Tentu saja kesan tersebut dilebih-lebihkan, sebab dalam kenyataannya di beberapa sektor para pengusaha pribumi tetap bertahan dan berkembang. Misalnya para pengusaha konveksi dan bordir di wailayah Kawalu yang muncul sejak tahun 1970-an. Area pemasaran dari industri kecil ini sangat luas, termasuk Pasar Tanah Abang. Namun harus diakui sebagian bahan baku, seperti kain, diperoleh dari toko-toko dan distributor pengusaha keturunan Tioghoa. Dalam bertransaksi, mereka sering menggunakan jaminan tanah. Di tengah fluktuasi harga bahan baku, para pengusaha pribumi sering merugi. Hutang dibayar oleh lahan. Dari kasus-kasus seperti inilah isu ketidakadilan ekonomi mendapatkan justifikasinya (Wawancara dengan KH Tb. Miftah Fauzi, 18 Mei 2016).

Politisi yang paling berhasil memanfaatkan situasi transisi di Tasikmalaya adalah Tatang Farhanul Hakim. Dia adalah Ketua Partai Persatuan Pembangunan (PPP). Dia menjabat ketua DPRD Tasikmalaya hasil Pemilu 1999. Dengan baik dia memanfaatkan kekecewaan publik terhadap Orde Baru untuk menggembosi dominasi Golkar yang telah berkuasa pada pemilu-pemilu sebelumnya. Di tangan dia pula para ajengan bendo dikonsolidasikan sehingga kelak mereka akan menjadi juru kampanye PPP yang handal. Hasilnya, PPP memenangkan Pemilu 1999. Dua tahun berikutnya, Tatang terpilih menjadi Bupati Kabupaten Tasikmalaya pasca-pemekaran. 
Kemunculan para ajengan bendo menandai kelahiran gerakangerakan Islam lokal Tasikmalaya yang dalam beberapa hal terkait dengan konstelasi nasional. Secara keagamaan mereka bercorak konservatif. Gerakan-gerakan ini timbul tenggelam mengikuti konstelasi politik lokal yang sangat dinamis dan, terutama lagi, figur kepemimpinannya. Salah satu gerakan yang pernah mencuat adalah Brigade Thaliban pimpinan $\mathrm{KH}$ Jenjen yang juga termasuk kalangan ajengan bendo. Gerakan ini sangat aktif menyuarakan "amar ma'ruf nahyi munkar" dengan mengadakan aksi-aksi sweaping terhadap objek-objek yang dianggap sebagai sarang kemaksiatan. Mereka juga rajin menggalang dukungan bagi pemberlakukan syariat Islam lewat peraturan daerah. Namun setelah pimpinannya meninggal pada 2013, pamor gerakan ini menurun.

Belakangan muncul gerakan yang menamakan dirinya Aliansi Masyarakat dan Aktivis Muslim Tasikmalaya (Al-Mumtaz) yang berdiri pada 2014 (Wawancara dengan Ust. Asep Sofyan, 23 Mei 2016). Gerakan ini, seperti terlihat dari namanya, merupakan aliansi dari beberapa organisasi Islam yang ada, seperti FPI, Jamaah Ansharu Shariah, Brigade Thaliban, dan lain-lain. Pimpinan gerakan ini mengklaim bahwa salah satu tujuan pendiriannya adalah untuk mengawal pelaksanaan Perda N0. 9/2014 tentang tata nilai di Kota Tasikmalaya. Mereka mau memastikan apakah perda tersbut direalisasikan atau tidak. Salah satu aksi mereka adalah penghentian paksa acara New Look Model Competition 2015 di sebuah mal yang dianggap hanya pamer aurat.

\section{Aktualisasi Ulang Ingatan Kolektif}

Berbeda dengan ormas Islam besar, seperti NU dan Muhammadiyah, gerakan-gerakan Islam lokal adalah fenomena kontemporer yang mendasarkan ideologinya pada ingatan kolektif setempat. Mereka membayangkan, lalu merekonstruksi, gerakannya sebagai kelanjutan dari gerakan serupa di masa lalu. Namun seperti dikatakan Budiawan, ingatan kolektif pada dasarnya tidak pernah berwajah tunggal. Ia selalu bersifat 
plural. Oleh karena itu, yang terjadi sesungguhnya adalah kontestasi ingatan kolektif. Masing-masing berebut pengaruh di tengah masyarakat. Di Tasikmalaya, setidaknya terdapat tiga genealogi yang menjadi sumber rujukan ingatan kolektif itu: Sarekat Islam, Masyumi, dan DI.

$\mathrm{KH}$ Tb. Miftah Fauzi, sekarang menjabat Ketua Partai Amanat Nasional (PAN) Kota Tasikmalaya, berpendapat bahwa sesungguhnya Tasikmalaya adalah kota SI atau SDI. Dia menolak pandangan bahwa Tasikmalaya adalah kota DI atau Masyumi. Jika melihat sejarah Tasikmalaya pada awal abad ke-20, demikian katanya, kita akan melihat peranan para haji yang sangat kuat. Mereka adalah pengusaha dan sekaligus penyebar Islam yang sangat gigih. Menurut Miftah Fauzi, model gerakan seperti inilah yang seharusnya sekarang direvitalisasi sebagai rujukan gerakangerakan Islam masa kini (Wawancara dengan KH Tb Miftah Fauzi, 18 Mei 2016).

Sementara itu, Asep Deni Bumaeri, Ketua Persatuan Umat Islam (PUI) dan juga Ketua Umum Partai Bulan Bintang (PBB) Kota Tasikmalaya, menyatakan bahwa bagaimanapun Masyumi yang merupakan partai politik terkuat di kota ini pada tahun 1950-an masih tetap berpengaruh hingga kini. Meski terpecah-pecah ke dalam berbagai partai politik, seperti PBB, PKS, PAN, PPP, dan bahkan Golkar, imajinasi mengenai kemenangan Masyumi di masa lalu tetap hidup di kalangan Muslim modernis perkotaan. Hingga kini kekuatan mereka tetap besar (Wawancara dengan Asep Deni Adnan Bumaeri, 16 Mei 2016).

Di sini lain lagi, KH Asep Maoshul Affandy menyebut bahwa Tasikmalaya adalah basis DI berasal dari. Pimpinan Pesantren Miftahul Huda, Manonjaya, Tasikmalaya, dan juga anggota DPR RI dari PPP ini menyatakan bahwa impian untuk menegakkan syariat Islam tidak pernah surut. Pada masa lalu hal itu berusaha diwujudkan oleh DI melalui aksi bersenjata, tetapi hal itu tidak diperlukan lagi. Dia menambahkan bahwa sekarang penegakan syariat Islam bisa dilakukan melalui kerangka hukum 
yang berlaku, seperti perda syariah (Wawancara dengan KH Asep Maoshul Affandi, 15 Mei 2016).

\section{Formalisasi Syariah}

Salah satu sorotan yang terus menerus diarahkan kepada Tasikmalaya adalah keberadaan regulasi bernuansa religius atau sering disebut "peraturan daerah (perda) syariah". Secara definitif memang tidak ada perda dengan nama perda syariah, tetapi beberapa peraturan daerah memang secara jelas mengekspresikan semangat syariah di dalamnya. Sejumlah tokoh agama dan politik setempat bangga dengan pencapaian itu. Adanya perda syariah menunjukkan bahwa Tasikmalaya adalah kota santri.

Di Kabupaten Tasikmalaya, perda syariah mengacu pada Perda No. 13/2001 tentang rencana strategis Kabupaten Tasikmalaya "yang religius/Islami sebagai pusat pertumbuhan di Priangan Timur serta mampu menempatkan diri menjadi kabupaten yang maju di Jawa Barat pada tahun 2010". Namun segera setelah itu visi ini mendapatkan beragam kritik, sehingga diganti menjadi "Tasikmalaya yang religius/ Islami sebagai kabupaten yang maju dan sejahtera serta kompetitif dalam bidang agribisnis di Jawa Barat tahun 2010”. Tidak lama setelah terbutnya perda ini, keluar pula Surat Edaran No. 451/SE/Sos/2001 tentang upaya peningkatan kualitas keimanan dan ketakwaan dan Keputusan Bupati Tasikmalaya Nomor 13/2003 451/Se/04/Sos/2001 tentang persyaratan memasuki jenjang pendidikan SD, MI, SMP, dan MTs yang dipandang sebagai implementasi dari visi religius/Islami tersebut.

Ketika itu semua partai politik di DPRD Kabupaten Tasikmalaya menyetujuinya. Tatang FH sebagai bupati merasa tidak ada yang salah dengan perda dan keputusan tersebut karena tidak bertentangan dengan konstitusi (Wawancara dengan Tatang FH, 23 Mei 2016). Perda syariah tidak bertujuan membentuk negara Islam seperti diperjuangkan oleh Negara Islam Indonesia (NII) di masa lalu, tetapi hanya untuk mengakomodasi 
kelompok Islam sebagai mayoritas di Tasikmalaya. Tatang menganggap hal itu wajar saja, sebab di tempat lain di mana mayoritasnya non-Islam seperti di Bali, dia meyakini hal serupa juga terjadi. Semuanya, dia menambahkan, tetap dilakukan dalam kerangka NKRI. Lebih lanjut Tatang menceritakan bahwa penetapan visi religius Islami tidak mengecilkan sama sekali kalangan non-Islam, sebab kata religius di sana mengacu pada semua agama. Dia mengaku paham bahwa hak-hak kewarganegaraan yang berlaku bagi semua warga negara tidak boleh dikesampingkan.

Akan tetapi, Tatang FH menyatakan bahwa kepentingan untuk menyatukan kelompok-kelompok Islam adalah alasan utama di balik penetapan perda tersebut. Penyatuan ini penting sebagai landasan bagi stabilitas demokrasi lokal di bawah pemerintahannya. Meski berasal dari latar belakang NU, Tatang berupaya merangkul semua kelompok Islam yang ada. Usahanya menghimpun para ajengan bendo justru dilakukan untuk mencegah kecenderungan radikal mereka. Dia selalu menekankan agar semua pihak menempuh jalan persuasi daripada konfrontasi. Dia menilai hal itu sebagai esensi demokrasi.

Mengenai kelompok minoritas dalam Islam, seperti Ahmadiyah, Tatang berpendapat bahwa masalah itu tidak akan pernah selesai sejauh tidak ada ketidaktegasan pemerintah pusat. Namun dia menyadari adanya dilema dalam perkara tersebut. Sebagai kepala daerah dia pernah mengalaminya. Pada satu sisi dia diminta mengikuti pandangan ulama yang menyatakan bahwa Ahmadiyah adalah sesat, tetapi pada sisi yang lain dia tahu bahwa sebagai kepala daerah dia harus berdiri netral. Untuk mengatasi dilema itu, dia hanya bisa meminta kepada para ulama agar tidak menggunakan cara kekerasan. Dia berharap para ulama menjalankan peran pokoknya sebagai misionaris untuk yaitu mengajak kembali Ahmadiyah ke jalan Islam.

Dukungan terhadap perda syariat datang dari gerakan-gerakan Islam lokal yang merasa bahwa Tasikmalaya sekarang berada dalam kemerosotan moral. Kalangan ini merasa bahwa Tasikmalaya kota santri hanyalah 
jargon yang tidak sesuai dengan kenyataan di lapangan. Bagi mereka, apa yang disebut sebagai "penyakit masyarakat", seperti narkoba, prostitusi, dan HIV/AIDS hanya bisa disembuhkan dengan agama (Wawancara dengan KH Aminuddin Busthomi, 17 Mei 2016). Oleh karena itu, agama harus diformalisasikan ke dalam peraturan daerah untuk membentengi masyarakat Tasikmalaya dari kemerosotan moral lebih jauh lagi.

Di Kota Tasikmalaya, mengikuti saudara tuanya di kabupaten, tuntutan akan suatu perda syariah terus digalakkan sejak awal. Salah satu promotor paling awal adalah KH. Tb Miftah Fauzi (Wawancara dengan KH Tb Miftah Fauzi, 18 Mei 2016). Dia mengumpulkan para tokoh agama dan politik untuk segera merealisasikan hal itu. Baginya, hampir sama dengan pendapat Tatang FH, perda syariah beda dengan negara Islam. Negara Islam sudah gagal, sedangkan perda syariah adalah peluang yang bisa digunakan oleh umat Islam di era demokrasi sekarang. Perda syariah tetap berada dalam bingkai konstitusi dan NKRI. Akhirnya lahirlah Perda No. 12/2009 tentang "pembangunan tata nilai kemasyarakatan yang berlandaskan pada ajaran agama Islam dan norma-norma sosial masyarakat Tasikmalaya". Perda ini ditandatangani oleh Syarif Hidayat, Walikota Tasikmalaya periode itu, yang berasal dari PPP.

Akan tetapi, Kementerian Dalam Negeri di bawah Menteri Gamawan Fauzi ketika itu sedang giat merevisi perda-perda bermasalah. Dia memanggil walikota ke Jakarta untuk merundingkan perda tersebut (Wawancara dengan Syarif Hidayat, 21 Mei 2016). Dia meminta perda tersebut direvisi. Kata "Islam" diminta dihapus karena suatu kebijakan publik seharusnya berlaku bagi semua, bukan hanya penduduk Muslim. Selanjutnya, 5 tahun kemudian, lahir Perda No. 7/2004 yang merupakan pengganti Perda No. 12/2009. Kata "Islam" telah dihapus. Judulnya diganti menjadi Perda tentang "tata nilai kehidupan masyarakat yang religius di Kota Tasikmalaya". Kata dan kalimat yang menyebutkan "Islam" secara khusus tidak dijumpai lagi, tetapi setelah diselidiki secara seksama substansinya kurang lebih sama. 
Tidak lama kemudian, melalui Keputusan Walikota Tasikmalaya No. 467.2/Kep.147-Kesbangpol/2005, Walikota Tasikmalaya, Budi Budiman, membentuk "tim koordinasi penerapan tata nilai kehidupan masyarakat yang religius di Tasikmalaya". Ketua tim dijabat oleh Sekretaris Daerah Kota Tasikmalaya, tetapi wakilnya adalah $\mathrm{KH}$ Amang Baden, seorang eksponen ajengan bendo. Tim ini mengklaim telah merangkul seluruh komponen ormas Islam, meski yang jelas tidak ada satu pun wakil dari kalangan non-Muslim di dalamnya. Namun dalam kenyataannya tidak semua kelompok Islam diikutsertakan dalam proses pembuatan perda tersebut. KH Didi Hudaya, Ketua PCNU Kota Tasikmalaya, mengaku tidak pernah diundang dalam pembahasan perda itu, meski namanya tercantum sebagai salah satu penasehat tim perda tersebut. Dia juga tidak tahu persis apa yang diatur oleh perda tersebut. Dia melihat perda tersebut hanyalah bentuk akomodasi pemerintah terhadap kelompok-kelompok Islam garis keras (Wawancara dengan KH Didi Hudaya, 11 Mei 2016).

Biaya pelaksanaan perda tata nilai tersebut dimasukkan ke dalam mata anggaran Kesbangpol Kota Tasikmalaya. Dalam pengakuan kepalanya, jumlahnya tidak banyak, hanya 300 juta rupiah per tahunnya. Sebagian besar anggaran itu digunakan untuk sosialisasi, termasuk kepada para pengusaha wisata agar melengkapi tempat usahanya dengan fasilitas ibadah yang memadai. Di setiap kamar hotel, misalnya, harus tersedia kitab suci dan arah kiblat. Pada pokoknya tempat-tempat wisata di Kota Tasikmalaya harus mencerminkan diri sebagi bagian dari citra kota santri.

\section{Simpulan}

Meski berbeda sumber geneologi, gerakan Islam lokal sepakat bahwa penerapan syariah melalui peraturan daerah adalah konstitusional, apalagi dalam sistem demokrasi yang berlaku di Indonesia sekarang. Di Tasikmalaya, mereka berargumen, Muslim adalah mayoritas, maka mereka mempunyai kesempatan untuk mengartikulasikan aspirasinya. Dalam sejarah, mereka menambahkan, Islam justru selalu melindungi 
kaum minoritas sejauh mereka mengikuti konsensus yang berlaku. Hal ini bukan khas Tasikmalaya; akan tetapi, istilah yang lebih tepat bagi kasus Tasikmalaya bukan "kebangkitan", tetapi "kebangkitan ulang", sebab itu merupakan keberlanjutan dari proses yang agak terhenti selama periode awal Orde Baru yang sekularistik.

\section{Referensi}

Habermas, Jurgen. 2008. "Notes on Post-Secular Society”, New Perspective Quarterly, September.

Hadad, Toriq. 1998. Amarah Tasikmalaya: Konflik di Basis Islam (Jakarta: ISAI, 1998)

Halbwachs, Maurice. 1992. On Collective Memory. Chicago/London: The University of Chicago Press.

Hefner, Robert W. 2004. "Shariah Formalism or Democratic Communitarianism" The Islamic Resurgence and Political Theory" dalam Chua Beng Huat (ed), Communitarian Politics in Asia. London/New York: Routledge.

Hefner, Robert W. 2011. Civil Islam, terj. Jakarta: ISAI.

Menchik, Jeremy. 2006. Islam and Democracy in Indonesia: Tolerance without Liberalism. Cambridge: Cambridge University Press.

Mudzakkir, Amin. 2005. Kaum Santri Kota: Pengusaha, Perubahan Ekonomi, dan Islam di Kota Tasikmalaya, 1930-1980-an, Skripsi Jurusan Sejarah FIB UGM, Yogyakarta, 2005

Noer, Deliar. 1996. Gerakan Moderen Islam di Indonesia 1900-1942. Jakarta: LP3ES.

Nora, Pierre. 1989. "Between Memory and History: Les Lieux de Mémoire”, Representations, No. 26, Spring, hlm. 7-24. 


\section{Sumber Wawancara}

Wawancara dengan KH Tb. Miftah Fauzi, 18 Mei 2016, di Tasikmalaya.

Wawancara dengan Ust. Asep Sofyan, 23 Mei 2016, di Tasikmalaya.

Wawancara dengan KH Tb Miftah Fauzi, 18 Mei 2016, di Tasikmalaya.

Wawancara dengan Asep Deni Adnan Bumaeri, 16 Mei 2016, di Tasikmalaya.

Wawancara dengan KH Asep Maoshul Affandi, 15 Mei 2016, di Tasikmalaya.

Wawancara dengan Tatang FH, 23 Mei 2016, di Tasikmalaya.

Wawancara dengan KH Aminuddin Busthomi, 17 Mei 2016, di Tasikmalaya.

Wawancara dengan KH Tb Miftah Fauzi, 18 Mei 2016, di Tasikmalaya.

Wawancara dengan Syarif Hidayat, 21 Mei 2016, di Tasikmalaya.

Wawancara dengan KH Didi Hudaya, 11 Mei 2016, di Tasikmalaya. 